\title{
Clinical and experimental substantiation of the use of bentonite suspension in the complex rehabilitation of patients with chronic viral hepatitis $\mathbf{C}$ with concomitant non-alcoholic fatty liver disease
}

\author{
IZHA Ganna ${ }^{1}$, DRAGOMIRETSKA Natalia ${ }^{1}$, GUSHCHA Sergey ${ }^{1}$, PLAKIDA Alexander ${ }^{2}$
}

Corresponding author: PLAKIDA Alexander: E-mail: aplakida@mail.ru

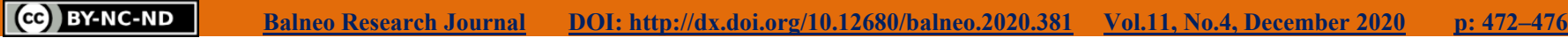

${ }^{1}$ State Institution «Ukrainian Research Institute of Medical Rehabilitation and Balneology of the Ministry of Health of Ukraine», Odessa, Ukraine

${ }^{2}$ Odessa National Medical University, Odessa, Ukraine

\begin{abstract}
Introduction. One of the most severe diffuse liver diseases is chronic viral hepatitis $\mathrm{C}(\mathrm{CHC})$ combined with non-alcoholic fatty liver disease (NAFLD). After completing the treatment of $\mathrm{CHC}$ with drugs of direct antiviral action, there remains a high risk of further progression of liver fibrosis associated with the presence of comorbid pathology - NAFLD in patients. The above circumstances initiated us to search for new non-drug technologies to treat this category of patients. Purpose of the work: to study the effectiveness of use bentonite suspension in rats with a model of NAFLD and to substantiate the practicality of using bentonite in the complex treatment of CHC patients with concomitant NAFLD. Methods: experimental, anamnestic and clinical, general clinical, biochemical, determination of the HOMA index, leptin and adiponectin levels, ultrasonographic studies of the digestive system, bacteriological examination of feces, statistical methods.Results: According to microscopic examination, bentonite application in animals with the NAFLC model leads to a decrease in liver steatosis, restoration of bile formation and bile secretion, and protein-synthesizing liver function. In the blood, there was a positive dynamics to the restoration of energy-dependent transmembrane ion transport according to the activity of $\mathrm{Na}^{+} / \mathrm{K}^{+}$-ATPase and $\mathrm{Mg}^{2+} / \mathrm{Ca}^{2+}$-ATPase (in the liver tissue) and the balance of the antioxidant system (to restrain malondialdehyde and catalase activity). We examined 40 patients with $\mathrm{CHC}$ with concomitant NAFLD, who completed the course of antiviral therapy (AVT) and were divided into two groups. 1 (control) group (20 people) received a basic treatment complex (diet therapy, which corresponded to the Mediterranean diet, a regimen of dosed physical exertion, patients of 2 groups ( 20 people, the main group) additionally received a preparation based on bentonite clay inside - 10 days ( 1 dose three times a day) Evaluation of the effectiveness of treatment was carried out one month after the start of treatment. Conclusion: The treatment carried out in both groups was accompanied by positive dynamics in most of the disease's symptoms. But a significant advantage was observed in the second group, where the normalization of cholestatic and dyslipidemic syndromes was established, that is, the effect on the pathogenetic links of the progression of NAFLD was proved. The results obtained confirm the practicality of using the drug with bentonite in the complex treatment of CHC patients with concomitant NAFLD.
\end{abstract}

Keywords: chronic viral hepatitis $C$, non-alcoholic fatty liver disease, bentonite clay,

\section{Introduction}

Modern scientific research is based on an in-depth study of the pathogenetic links of various chronic diseases of internal organs and the subsequent formation of adequate therapy regimens. The issue of treatment of patients with comorbid conditions is fundamental. The combination of nosological forms can cause disease progression, early complications, and correction of therapeutic measures. Among the diffuse liver diseases that are most often combined, there is chronic viral hepatitis $\mathrm{C}(\mathrm{CHC})$ with non-alcoholic fatty liver disease (NAFLD) $(1,2)$.

NAFLD acts as the main comorbid factor in the development of liver damage caused by CHC. This interaction is in a shorter time the appearance and progression of fibrosis, from initial to advanced stages. On the one hand, the hepatitis C virus itself can cytotoxically lead to direct liver damage, trigger a genotype-specific way or indirectly, through the insulin pathway, to develop fatty liver damage. On the other hand, the presence of such risk factors as insulin resistance, diabetes mellitus, obesity, intestinal dysbiosis, and epigenomic breakdowns lead to the independent formation of NAFLD, which aggravates the course of the necrobiotic process in the liver tissue and the progression of fibrosis, which remains relevant even in patients who have completed the course antiviral therapy (AVT) and achieved sustained virological response (SVR) $(3,4)$.

Studies in the field of assessing the factors of interaction along the "intestine-liver" axis show that a targeted effect on various elements of this pathophysiological vector, including the impact on the qualitative and quantitative composition of the intestinal microflora, can slow down the progression of fibrosis in chronic liver diseases and improve the prognosis for the patient. $(5,6)$.

Modern studies of human microflora suggest the central role of microbiota and impaired intestinal permeability in the development of NAFLD; however, to establish exact pathogenetic mechanisms, it is necessary to continue research in this direction $(7,8)$. In this aspect, the intestinal microflora's pharmacological modeling may be a promising therapeutic strategy in diffuse liver diseases such as NAFLD $(9,10)$.

Returning to comorbidity as a potential risk factor for further progression of fibrosis in patients after achieving a sustained virological response (SVR), it should be noted that there are limited opportunities in the field of treatment of these 
conditions. For example, the European Association for the Study of the Liver's clinical guidelines indicates the need to prescribe drug therapy for NAFLD in patients who have either signs of NASH in the presence of fibrosis F2 or higher or the risk of disease progression. Currently, only vitamin $\mathrm{E}$ and pioglitazone are recommended (11). Several new drugs for NAFLD treatment continue to remain at various stages of clinical trials $(12,13)$.

Given the above, it becomes evident that the use of only antiviral therapy in this category of patients will not solve NAFLD's problem. In this regard, the treatment of patients with $\mathrm{CHC}$ and NAFLD should be comprehensive and consistent.

Considering that today modern science recognizes the essential role of the intestinal microbiota in the occurrence and progression of hepatic steatosis to steatohepatitis, it seems interesting to study the state of the intestinal microbiota (their qualitative and quantitative state) in patients with NAFLD and CHC, as well as the effectiveness of drinking a drug based on bentonite clay. - "Smectoite omega". The basis for this drug's use of was preliminary complex experimental studies, which found that a solution of bentonite clays has ion-exchange, colloidal, absorption properties and promotes the elimination of exo- and endogenous toxic substances from the body $(14,15)$.

That is why we carried out our own experimental and clinical studies, the purpose of which was to study the effectiveness of taking a suspension of bentonite in rats with a model of NAFLD, and the subsequent substantiation of the advisability of using a drug based on bentonite in the complex treatment of patients with $\mathrm{CHC}$ with concomitant NAFLD.

Materials and methods. The study included two stages experimental and clinical Experimental studies were carried out following existing guidelines and legal documents (16). Forty white Wistar rats were divided into three groups. Group 1 consisted of intact animals - the control group (16 rats), which received a regulal diet and had free access to drinking bowls with tap water, Group 2 (12 rats) consisted of animals with the NAFLD model. Group 3 (12 rats) consisted of animals with the NAFLD model, who received a course of bentonite clay (2.5\% aqueous solution) from day 30 . The solution was injected into the esophagus with a soft probe with an olive, at a dose of $1 \%$ of the animal's body weight, once a day, for 12 days.

According to its chemical composition, the water extract of bentonite clay of bentonite is a liquid phase of bentonite and consists of salts dissolved in water. The amount of dissolved salts is $0.30 \%$, the bulk of which is represented by bicarbonate ions $(0.15 \%)$, sodium and potassium ions, sulfate ions $(0.06 \%)$, calcium ions, and chloride ions $(0.04 \%)$.

The experiment lasted 42 days. To reproduce the NAFLD model, animals of groups 2 and 3 received, in addition to the standard diet (complete feed and grain mixture in an amount of $20 \mathrm{~g}$ ), $5 \mathrm{~g}$ of beef fat rubbed with $10 \mathrm{~g}$ of white crackers per 1 animal and consumed only $10 \%$ fructose solution as a drink on distilled water. On the twentieth day, animals of 2 and 3 groups were injected with $\mathrm{CCl} 4$ at the rate of $0.1 \mathrm{ml}$ per $200 \mathrm{~g}$ of body weight. Upon completion of the study, the animals were removed from the experiment under ether anesthesia. A piece of liver was prepared from the rats, than it was passed through alcohols of increasing concentration and poured into celloidin. Subsequently, histological sections were prepared, stained with hematoxylin-eosin, and microscopic studies of structural changes in the liver were carried out.

In the blood serum, the activity of transamination enzymes, alanine aminotransferase (ALT) and aspartate aminotransferase (AST), the activity of $\mathrm{Na}^{+} / \mathrm{K}^{+}$dependent ATPase, and $\mathrm{Mg}^{2+} / \mathrm{Ca}^{2+}$ dependent ATPase in the liver tissue homogenate (providing the energy supply of cells), indicators of pigment metabolism - total bilirubin and its fractions; determined the content of total protein and its fraction (albumins, $\alpha 1-, \alpha 2-, \beta-, \gamma$-globulins), the content of urea, creatinine. The state of the antioxidant system (AOS) was investigated by the activity of catalase, the state of the prooxidant system/peroxidative oxidative lipids (LPO) - by the content of malondialdehyde (MDA).

The level of glucose and triglycerides was also determined in blood serum. The techniques used in the research are published in the guidelines $(17,18)$. The data obtained were compared with the corresponding indicators of group 1 of rats. Statistical processing of data was carried out using the programs for biomedical research Statistica. According to the Student's tables $(\mathrm{p}<0.05)$, significant changes were considered those within the confidence limits.

The clinical study used anamnestic and clinical methods. Evaluated: the severity of pain, dyspeptic, asthenic syndromes, studied general clinical and biochemical blood parameters, including lipid metabolism and the level of adipocytokinins. Insulin resistance (IR) was assessed according to the HOMA index. Ultrasonographic studies (ultrasound) of the digestive organs and bacteriological examination of feces were carried out. The generally accepted variation statistics methods processed the results obtained, the mean values, their errors, and the FischerStudent test of reliability were calculated.

The study was carried out on 40 patients with $\mathrm{CHC}$ (genotype $1 \mathrm{~b}$ in the phase of replication, minimal and moderate degrees of activity) with concomitant NAFLD. In all the examined patients, NAFLD was represented by nonalcoholic steatohepatitis of minimal activity. Among the patients, women predominated, the average age was (52.67 \pm 2.14) years. All patients completed a 3-month course of AVT (sofosbuvir $(400 \mathrm{mg}$ ) and ledipasvir $(90 \mathrm{mg})$ ) and received an SVR 12 weeks after completion of treatment.

The patients were divided into two groups. 1 (control) group (20 people) received the basic complex of treatment (diet therapy, dosed physical activity), patients of 2 groups (20 people, the main group) additionally received inside the drug based on bentonite clay "Smektovit omega" - 10 days ( 1 dose three times a day). Evaluation of the effectiveness of treatment was carried out one month after the start of treatment. The chemical composition of the drug 
"Smektovite omega" in 1 dose (10 g) contains bentonite4 $490 \mathrm{mg}$, sodium - $10 \mathrm{mg}$, flaxseed oil - $500 \mathrm{mg}$, wheat germ oil - $500 \mathrm{mg}$, drinking water $-8.5 \mathrm{sm}^{3}$.

Results and discussion. In rats of group 2, microscopic examination revealed the preservation of the lobular organization of the parenchyma. In a significant number of hepatocytes, lipid vacuoles of multiple dimensions are observed. The inter-girder spaces are expanded, Kupffer cells with rounded nuclei. Between the lobules and in some of them, homogeneous inclusions of various sizes with eosinophilic coloration are observed. In the study of metabolic parameters, a significant increase in ALT activity, and a decrease in AST activity are determined, which indicates a violation of the flow and balance of transamination processes (Table 1).

It can be considered that these changes indicate a violation of the permeability of cell membranes. The amount of bilirubin significantly increases, while the ratio of its fractions slightly changes (the content of direct bilirubin increases), which indicates a decrease in the function of bile formation and detoxification of the liver. The amount of total protein significantly decreases; that is, protein synthesis in the liver is suppressed.

The content of proteins is also changing: the content of $\alpha 2-$, $\beta$ - and $\gamma$-globulins significantly decreases, the content of albumin and $\alpha 1$-globulin does not change reliably; that is, there is not only a change in the intensity of protein synthesis but also its imbalance. A significant increase in the activity of $\mathrm{Mg}^{2+} / \mathrm{Ca}^{2+}$-ATPase and a decrease of $\mathrm{Na}^{+} / \mathrm{K}^{+}$-ATPase were found, which indicates an imbalance in the activity of transmembrane transport. The power supply of $\mathrm{Mg}^{2+}$ and $\mathrm{Ca}^{2+}$ pumps is increased. The results obtained suggest that the used model of NAFLC causes dystrophic changes in the liver parenchyma with the accumulation of lipid inclusions, which are caused by systemic metabolic disorders.

The need for these ions to ensure the vital activity of cells increases significantly. A significant increase in the MDA content and a decrease in catalase activity were revealed. Consequently, the LPO/AOD system's activity is unbalanced, which creates conditions for damage to cell membranes. An increase in the content of glucose and triglycerides was found, which indicates the inhibition of the intensity of carbohydrate and lipid metabolism and, consequently, the deposition of excess lipid inclusions in hepatocytes.

Table 1. Dynamics of the main biochemical parameters in experimental animals under conditions of reproduction of the NAFLD model with internal course intake of bentonite suspension, $(\mathrm{M} \pm \mathrm{m})$

Note: * - significant changes $(\mathrm{p}<0.05)$ are calculated in comparison between 1 and 2 groups; ** - significant changes $(p<0.05)$ were calculated in comparison between groups 1 and 3 .

In rats of group 3, microscopic examination showed that the parenchyma's local organization is preserved, the hepatocytes are the same, of average size. Their cytoplasm is homogeneous, weakly basophilic. Hepatocytes on 2/3 of

\begin{tabular}{|c|c|c|c|}
\hline Ind & $1 \mathrm{st}$ & $2 n$ & \\
\hline MDA, $\mathrm{nmol} /(\min \times$ & $5,94 \pm 0,21$ & $7,49 \pm 0,30 *$ & $5,87 \pm 0,34$ \\
\hline Catalase, $\%$ & $76,70 \pm 1,52$ & $72,42 \pm 1,57 *$ & $77,0 \mathrm{C}$ \\
\hline AST & & & \\
\hline$\times \mathbf{x h}$ & 57 & 252 & \\
\hline De Ritis & 2,10 & 1,5 & 1,9 \\
\hline Tota & 5,79 & & \\
\hline$\overline{\text { Bilir }}$ & 1,98 & 2,8 & 6 \\
\hline Bili & 3,8 & & \\
\hline & 68 & & $9 * *$ \\
\hline$/ 1$ & 25,8 & 22 & 1,40 \\
\hline$\alpha-1 \mathrm{GI}$ & 8,28 & & \\
\hline 8 & 20 & & 6,0 \\
\hline$\beta-\mathbf{G l}$ & 11,8 & & 30 \\
\hline$\gamma$ - Glo & 111 & & 25 \\
\hline Iucos & & & 29 \\
\hline Trig & & & $0,08 * *$ \\
\hline $\begin{array}{r}\mathrm{Mg}^{2+} / \mathrm{Ca}^{2+}-\mathrm{AT} \\
\mathrm{P} / \mathrm{h} \times \cdot \mathrm{mg} \text { pl }\end{array}$ & $9,11 \pm 0,93$ & $11,75 \pm 0,67 *$ & $10,14 \pm 0,27$ \\
\hline $\mathbf{N a}^{+} / \mathbf{K}^{+}-\mathbf{T}$ & & 3, & \\
\hline
\end{tabular}

the area of the lobules are collected in beams. On the periphery of the lobule, the separation of the beams is difficult. Interbeam spaces are widened, Kupffer cells with small oval nuclei.

In some lobules, single hepatocytes with vacuoles of medium or small sizes are found. The positive effect on the state of metabolic parameters in rats of group 3 is given in detail in Table 1. The activity of ALT and AST recovered to the control level. As a result of these changes, the de Ritis index differs little from the indexe of intact animals, that is, signs of damage to hepatocyte membranes disappear, lipoprotein metabolism is restored, and detoxification processes are approaching normal.

Positive protein metabolism changes were revealed: the content of total protein in the blood almost reaches the normal level, and the protein fractions are practically restored. The content of simple proteins (albumin) increases, while the range of more complex proteins (globulins) remains less than control.

A positive trend was established in terms of the indicators of the LPO/AOD system: the content of MDA, the final LPO product, returns to the target figures, and the catalase activity is restored. This characterizes the improvement of the conditions for cell membranes' functioning and has a positive effect on vital processes. The activity of $\mathrm{Na}^{+} / \mathrm{K}^{+}$-ATPase is restored. The activity of $\mathrm{Mg}^{2+} / \mathrm{Ca}^{2+}$-ATPase remains less than in control, but the imbalance of their activity decreases, which can be considered a tendency to improve transmembrane transport.

The normalization of the activity of $\mathrm{Mg}^{2+} / \mathrm{Ca}^{2+}$-ATPase, together with an improvement in the of the membranes' state due to the restoration of the LPO / AOD system, suggests that the supply of $\mathrm{Mg}^{2+}$ and $\mathrm{Ca}^{2+}$ on the membranes is restored. In parallel, there is a decrease in pathological changes in lipid and carbohydrate metabolism. Thus, the internal course administration of a suspension of bentonite in rats with the NAFLD model reduces the metabolic changes of a pathological nature inherent in this disease. 
The obtained results of experimental studies have proved the feasibility of using a bentonite solution in animals with a model of NAFLD, which became the basis for the use of the drug "SMEKTOVIT omega" in clinical trials.

A low-symptom course characterized the clinical picture of NAFLD in the studied patients. Only a third of the patients were concerned about pain syndrome (severity or pain in the right hypochondrium, pain on palpation of this area). The majority of patients $(62.50 \%)$ presented complaints characterizing intestinal dyspepsia (flatulence, increased gas production), which were more associated with concomitant disorders of the microflora of the large intestine. Complaints describing asthenic syndrome (weakness, increased fatigue, decreased performance) were identified in $35.0 \%$ of the surveyed. The overwhelming majority of patients $(82.50 \%)$ have overweight (BMI) or obesity grade I-II. BMI is equal on average $\left(31.97 \pm 1.15 \mathrm{~kg} / \mathrm{m}^{2}\right)$.

A biochemical study revealed an increase in total bilirubin level due to its indirect fraction in $35.0 \%$ of patients, the level of alkaline phosphatase, and gam-glutamate transferase up to $1.5 \mathrm{~N}$ - in $32.5 \%$. The cytolytic syndrome was found in $17.5 \%$ of the examined patients. Lipid metabolism disorders were characterized by an increase in the level of total cholesterol (TC) on average to $(6.65 \pm 0.18) \mathrm{ng} / \mathrm{ml}, \beta$ lipoproteins - $(66.21 \pm 2.13)$ units, triglycerides - $(3.15 \pm$ $0.12) \mathrm{mmol} / \mathrm{l}$, LDL on average to $(4.19 \pm 0.27) \mathrm{ng} / \mathrm{ml}$, decrease in HDL level on average in the group to $(1.33 \pm$ $0.15) \mathrm{ng} / \mathrm{ml}$.

The atherogenic coefficient averaged (4.59 \pm 0.33$)$ units. When studying the carbohydrate metabolism parameters, the blood serum glucose level averaged in the group (5.86 \pm $0.39) \mathrm{mmol} / \mathrm{l}$. The insulin concentration was slightly increased and averaged $(19.24 \pm 0.97) \mu \mathrm{U} / \mathrm{ml}$. The HOMA index was $(4.52 \pm 0.43)$ units, which indicates a pronounced insulin resistance in the examined patients. The level of leptin in patients was increased and averaged $(29.12 \pm 3.52)$ $\mathrm{ng} / \mathrm{ml}$, the level of adiponectin was decreased and averaged $(12.16 \pm 1.85) \mathrm{ng} / \mathrm{ml}$.

According to the bacteriological study of feces for dysbiosis, before treatment, $100 \%$ of the examined patients were found to have quantitative and qualitative changes in the colon microflora composition. Thus, in $65.0 \%$ of patients, grade II colon dysbiosis was diagnosed, in $20.0 \%$ of patients - grade I colon dysbiosis, in $15.0 \%$ - grade III colon dysbiosis. In $70.0 \%$ of patients, a significant decrease in the number of bifidobacteria was determined, in $55.0 \%$, to reduce of the number of lactobacilli.

Against the background of a decrease in the total number of esherichia, a reduction of bifidobacteria and lactobacilli was diagnosed $-65.0 \%$ of cases. Simultaneously, the decline in the total number of esherichia was accompanied by the appearance among them of hemolyzing (40.0\%) and lactosenegative $(25.0 \%)$ species of E. coli, that is, microorganisms with opportunistic and pathogenic properties. In $45.0 \%$ of patients, pathogenic and opportunistic microorganisms were identified in the form of St. aureus $(10.0 \%)$, clostridium
$(10.0 \%)$, Proteus Vulgaris $(5.0 \%)$, fungi of the genus Candida $(20.0 \%)$.

The results of the ultrasound examination in $100 \%$ of patients showed sonographic signs of hepatic steatosis (diffuse increase in the "brightness" of the hepatic parenchyma, distal attenuation of the echo signal, blurred vascular pattern, its "blurring"), hepatomegaly was detected in $67.5 \%$ of patients.

Analysis of the treatment results, carried out a month later, showed an improvement in the disease's clinical course, mainly in patients of group 2 .

It should be specially noted a positive effect on the elimination of signs of intestinal dyspepsia (flatulence, gas formation) in patients of the main group, in contrast to the control group, where no significant changes occurred $(\mathrm{p}>$ $0.5)$. Only in the main group of patients was a significant positive effect determined elimination of manifestations of asthenic syndrome $(\mathrm{p}<0.001)$ - general weakness, rapid fatigue.

Under the influence of this treatment complex, an exact positive effect was revealed in eliminating the manifestations of pain syndrome; at the end of treatment, only $5.0 \%$ of the examined main group of patients complained of pain in the right hypochondrium. In contrast, signs of pain syndrome remained in $15.0 \%$ of patients in the control group.

In all examined patients who had an increased BMI at the beginning of treatment, a significant $(p<0.001)$ decrease in body weight was determined at the end of treatment; the average BMI in the group was $(25.89 \pm 1.07) \mathrm{kg} / \mathrm{m}^{2}$.

A biochemical study demonstrated a significant $(\mathrm{p}<0.05)$ elimination of a cytolytic syndrome's signs in all examined patients. Normalization of total bilirubin level $(p<0.01)$ and markers of cholestasis $(\mathrm{p}<0.05)$ was determined only in patients of group 2. Also, patients in group 2 showed a significant decrease in the concentration of total cholesterol $(\mathrm{p}<0.01)$, triglycerides $(\mathrm{p}<0.05), \beta$-lipoproteins $(\mathrm{p}<0.01)$, LDL $(\mathrm{p}<0.05)$, as well as a tendency to an increase in HDL ( $p>0.05$ ), in contrast to patients of group 1, in whom the changes were insignificant $(p>0.5)$. Also, in patients of group 2, significant changes in carbohydrate metabolism were determined, which were characterized by positive dynamics of insulin resistance according to the HOMA index $(\mathrm{p}<0.05)$.

Positive dynamics in group 2 characterized the change in the level of adipocytokines. Thus, the level of adiponectin significantly increased and averaged $(22.05 \pm 2.12) \mathrm{ng} / \mathrm{ml}(\mathrm{p}$ $<0.05$ ), and the change in the level of leptin was characterized by a downward trend, which averaged over the group $(15.73 \pm 3.77) \mathrm{ng} / \mathrm{ml}(\mathrm{p}>0.05)$.

Bacteriological examination of feces showed a significant correction of dysbiotic disorders in the colon in patients'main group. At the end of treatment, most patients were diagnosed with a significant increase in the concentration of bifidobacteria $(\mathrm{p}<0.001)$, lactobacilli $(\mathrm{p}<0.001)$, the total number of escherichia ( $p<0.001)$. The number of microorganisms of pathogenic microflora also significantly decreased, namely, the concentration of E. coli with 
hemolyzing and lactose-negative properties decreased ( $p$ $<0.001)$, St. aureus $(\mathrm{p}<0.05)$, Proteus Vulgaris $(\mathrm{p}<0.05)$, fungi of the genus Candida $(\mathrm{p}<0.05)$, clostridium $(\mathrm{p}<0.05)$. No significant changes in the ultrasound picture of the liver were observed. However, one-third of patients in group 2 showed an improvement in the organ's visualization, a decrease in the acoustic density of the liver parenchyma, and an improvement in the passage of an ultrasound signal into its deep layers.

Comparative analysis between patients of the 1st control and 2nd group indicates a greater therapeutic efficiency of the therapeutic complex with the a preparation based on bentonite clay.

\section{Conclusions}

1. Under the influence of a course intake of a suspension of bentonite, a decrease in the manifestations of lipid degeneration of hepatocytes was microscopically established. Also, the restoration of carbohydrate metabolism indicators, detoxification, bile-forming, bile-excreting, and proteinsynthesis functions of the liver and restoration of energy supply of transmembrane transport was determined.

2. The complex application of the Mediterranean diet, physical activity, bentonite suspension contributes to reliable ( $p<0.001)$ elimination of clinical signs of NAFLD, a significant decrease in body weight ( $p<0.001)$, normalization of the functional state of the liver, especially lipid profile $(\mathrm{p}<0.001)$, reliable $(\mathrm{p}<0.001)$ correction of the quantitative and qualitative composition of the colon microflora, restoration of adiponectin secretion and the ultrasound picture of the liver.

3. Complex rehabilitation with the use of a preparation based on bentonite clay "Smectoite omega" contributed to the favorable dynamics of the clinical course of the disease, improvement of the functional state of the liver, normalization of lipid metabolism, decrease in insulin resistance, restoration of the intestinal microbial landscape, restoration of adiponectin secretion - key pathogenetic factors in the formation and progression of non-alcoholic fatty liver disease

\section{References:}

1. Coppola N, Alessio L, Onorato L. et al. Epidemiology and management of hepatitis $\mathrm{C}$ virus infections in immigrant populations. Infect Dis Poverty. 2019;8, 17. https://doi.org/10.1186/s40249-019-0528-6.

2. Younossi ZM, Golabi P, Avila L, Paik JM, Srishord M. et al. The global epidemiology of NAFLD and NASH in patients with type 2 diabetes: A systematic review and meta-analysis. Journal of Hepatology.

https://doi.org/10.1016/j.jhep.2019.06.021

2019;71(4):793-801.

3. Miele L, Marrone $\mathrm{G}$, Lauritano $\mathrm{C}$, et al. Gut-liver axis and microbiota in NAFLD: insight pathophysiology for novel therapeutic target. Curr Pharm Des. 2013;19(29):5314-5324. https://pubmed.ncbi.nlm.nih.gov/23432669/

4. Zhdanov KV, Kozlov KV, Sukachev VS, Zaharenko SM, Karyakin SS. Elimination of hev-infection: a history with continuation. J Infectology. 2018;10(4):6-13. doi: 10.22625/2072-6732-2018-104-6-13. (in Russian).

5. Chikhacheva E, Seliverstov P, Teterina L, Dobritsa V, Radchenko V. Enteric microbiocenosis in chronic liver diseases: diagnosis and treatment. Vrach (The Doctor). 2011;(7):18-21. http://gastro.rusvrach.ru/archive/vrach-2011-07-05.pdf Russian).

6. Malaguarnera $M$, Vacante $M$, Antic $T$. et al. Bifidobacterium longum with fructo-oligosaccharides in patients with non alcoholic steatohepatitis. Dig. Dis. Sci. 2012;57(2):545-553. doi 10.1007/s10620-011-1887-4.

7. Fukui H. How leaky gut and endotoxemia induce bacterial infection in cirrhosis and gastrointestinal hemorrhage? J.Gastroenterol. Hepatol. 2011;26 (3):423-425. https://doi.org/10.1111/j.1440-1746.2011.06668.x.

8. Roychowdhury S, Selvakumar PC, Cresci GAM. The Role of the Gut Microbiome in Nonalcoholic Fatty Liver Disease. Med Sci (Basel). 2018;6(2):47. doi:10.3390/medsci6020047.

9. Tkach SM, Cheverda TL, Kaznodiy AV. The role of enterohepatic association and intestinal microbiota in the development of nonalcoholic fatty liver disease. Modern Gastroenterology. 2015;5(85):96-108. http://nbuv.gov.ua/UJRN/SGastro_2015_5_16. (in Ukranian).

10. Perumpail BJ, Li AA, John N, et al. The Therapeutic Implications of the Gut Microbiome and Probiotics in Patients with NAFLD. Diseases. 2019;7(1):27. doi:10.3390/diseases7010027 ).

11. European Association for the Study of the Liver (EASL); European Association for the Study of Diabetes (EASD); European Association for the Study of Obesity (EASO). EASL-EASD-EASO Clinical Practice Guidelines for the management of non-alcoholic fatty liver disease. J Hepatol. 2016;64(6):1388-1402. doi:10.1016/j.jhep.2015.11.004

12. Konerman MA, Jones JC, Harrison SA. Pharmacotherapy for NASH: Current and emerging. J Hepatol. 2018; 68:362-75.

13. Pydyn N, Miękus K, Jura J. et al. New therapeutic strategies in nonalcoholic fatty liver disease: a focus on promising drugs for nonalcoholic steatohepatitis. Pharmacol. Rep. 2020;72:1-12. https://doi.org/10.1007/s43440-019-00020-1.

14. Alekseenko NA, Gushcha SG, Zmiyevskyi AV. Effect of bentonite clays on the development of chronic alcohol intoxication in the experiment. Environment \& Health. 2014;1(68):17-21. http://www.dovkil-

zdorov.kiev.ua/publ/dovkil.nsf/all/cnum?opendocument\&stype $=42$ 98F1A8BFF6E571C2257CB4002A7F0D (in Ukranian).

15. Nasibullin BA, Gushcha SG, Oleshko OYa, Zmiyevskyi AV, Savitskyi IV. Corrective influence $2.5 \%$ suspension of glauconitic clay on the structural and metabolic manifestations of stressinduced endogenous intoxication. Balneo Research Journal. 2015;6(3):143-146. doi: 10.12680/balneo.2015.1096.

16. Directive 2010/63/EU of the European Parliament and of the Council of 22 September 2010 on the protection of animals used for scientific purposes (Text with EEA relevance) // Official Journal. 2010;276:0033-0079. https://eurlex.europa.eu/LexUriServ/LexUriServ.do?uri=OJ:L:2010:276:0033 :0079:EN:PDF

17. Nakaz MOZ Ukraïni vid 28.09.2009 r. № 692 «Pro zatverdzhennja metodichnih rekomendacij z metodiv doslidzhen' biologichnoï dii prirodnih likuval'nih resursiv ta preformovanih likuval'nih zasobiv»». Order of MOH of Ukraine No. 692 dated 28.09.2009 «On approval of the recommendations of the research methods of biological effects of natural medicinal resources and preformed remedies».

http://old.moz.gov.ua/ua/portal/dn 20090928 692.html

URL: Ukranian).

18. Gorjachkovskij AM. Klinicheskaja biohimija v laboratornoj diagnostike. izd. 3-e. Clinical biochemistry in laboratory diagnostics Odessa: Jekologija, 2005. 608 s (in Russian). 